\title{
Estimation of Energy Efficiency of Means of Transport According to the Results of Technical Diagnostics
}

\author{
Anton Shalkov ${ }^{1}$, and Mariya Mamaeva ${ }^{1}$ \\ ${ }^{1}$ Prokopievsk branch of T. F. Gorbachev Kuzbass State Technical University, 653039, 19a \\ Nogradskaya St., Prokopievsk, Russia
}

\begin{abstract}
The article considers the questions of application of nondestructive methods control of reducers of conveyor belts as a means of transport. Particular attention is paid to such types of diagnostics of technical condition as thermal control and analysis of the state of lubricants. The urgency of carrying out types of nondestructive testing presented in the article is determined by the increase of energy efficiency of transport systems of coal and mining enterprises, in particular, reducers of belt conveyors. Periodic in-depth spectral-emission diagnostics and monitoring of a temperature mode of operation oil in the operation of the control equipment and its technical condition and prevent the MTBF allows the monitoring of the actual technical condition of the gearbox of a belt conveyor. In turn, the thermal imaging diagnostics reveals defects at the earliest stage of their formation and development, which allows planning the volumes and terms of equipment repair. Presents diagnostics of the technical condition will allow monitoring in time the technical condition of the equipment and avoiding its premature failure. Thereby it will increase the energy efficiency of both the transport system and the enterprise as a whole, and also avoid unreasonable increases in operating and maintenance costs.
\end{abstract}

\section{Introduction}

In the Russian Federation, as in many other developed countries, transport is one of the largest sectors of the economy, and an important part of the production infrastructure. The transport system connects all regions of the country, which is a necessary condition of its territorial completeness. In turn, the wide application of transport communications across the country and across the enterprise makes us think about energy efficiency in the transport system as a whole in view of annual growth of energy consumption, negative impact on the environment and emissions of harmful substances, unjustified increase of costs of operation and maintenance of the equipment [1].

One of the most common means of moving bulk materials is continuous transport system, including belt conveyors. Particularly widespread they last received in coal and mining industry as an intermediate and main conveyor systems high performance, providing transportation of goods over long distances. 
The problem of increasing energy efficiency and achieving energy savings is a priority for the country's economy in general and for the mining sector specifically. A new research direction is being currently developing, which develops the theoretical foundations of energy conservation and efficiency, and accumulates experience of their practical implementation $[4,9,10]$. One of the methods of diagnosing the technical condition of the transport unit (e.g. a belt conveyor or dump truck) as a means of transport is a method of nondestructive testing [5]. One of the important elements of nondestructive control is a thermal control and analysis of lubricant condition.

\section{Materials and methods}

Operating temperature of lubricants that meets the standards of GOST28549.9-90 is of great importance for efficient operation of the transport unit. Raising appropriate temperature standards, lubricants degrade their lubricating property which leads to increased wear of the working friction surfaces and bearing units. In practice, the heating of the reducer is determined by the "manual", and often it does not give reliable information. For this reason, it is advisable to use an integrated approach: continuous monitoring of a temperature mode and periodic in-depth spectral emission diagnostics of the working oil. Spectral analysis of the impurities contained in the transmission fluid determines the concentration of wear products. While diagnosing oil the following parameters are determined: kinematic viscosity, flash point in open crucible, the water content and the products of wear $[1,2]$. Particles of metal, indicating the technical condition of friction work surfaces and bearing units are iron, copper, chromium, Nickel and silicon. At a constant excess of any of these metallic elements in the lubricant you need to perform diagnostics of gears, splines and bearings. Only silicon content excess in oil says that the oil is worn out and needs to be fully replaced. Oil change should be made in the case of the gradual accumulation therein of metal particles, which concentration is close to or exceeds the limit value. The presence of small amounts of copper particles in the oil is normal; it is due to the use of bearings with brass cages.

The increase in the concentration of the content of the copper particles in the lubricant indicates the beginning of an intense wear of the cage, and when exceeding the limit values of the content of these pieces of brass can be visually observed in the oil, which is poured in a glass test tube, in the form of a golden glitter. In such cases the oil must be replaced. To perform diagnostics of bearing units is also necessary and in need also will be replaced [2, $3,8]$. This service allows reducing repair costs, preventing emergency downtime and increasing energy efficiency as a transport unit in particular and the enterprise in general [9$10]$.

\section{Results and discussion.}

In practice, when periodic analysis of the technical condition of the gear oil in gear boxes of belt conveyors for mining-revealed their incompatibilities with normative values (GOST 23652-79) of the main physical-chemical parameters were revealed. The obtained results are presented in tables $1-4$.

Table. 1 Organoleptic studies

\begin{tabular}{|c|c|c|c|c|c|}
\hline \multirow{2}{*}{ Settings } & Sample & Sample & Sample & Sample & Sample \\
& $\mathbf{1 5 . 0 5 . 1 5}$ & $\mathbf{1 8 . 0 9 . 1 5}$ & $\mathbf{4 . 1 2 . 1 5}$ & $\mathbf{1 7 . 0 6 . 1 6}$ & $\mathbf{2 0 . 1 0 . 1 6}$ \\
\hline Appearance & Dark brown & Dark brown & Dark brown & Dark brown & Dark brown \\
\hline
\end{tabular}




\begin{tabular}{|c|c|c|c|c|c|}
\hline $\begin{array}{c}\text { The } \\
\text { presenceof } \\
\text { water }\end{array}$ & Itisnotrevealed & Itisnotrevealed & Itisnotrevealed & Itisnotrevealed & Itisnotrevealed \\
\hline $\begin{array}{c}\text { The presence } \\
\text { of insoluble } \\
\text { particles on } \\
\text { filter paper }\end{array}$ & Include & Include & Include & Itisnotrevealed & Itisnotrevealed \\
\hline
\end{tabular}

Table. 2 Kinematic viscosity

\begin{tabular}{|c|c|c|c|c|c|c|}
\hline \multirow{2}{*}{$\begin{array}{c}\text { Temperat } \\
\text { ure, }{ }^{\circ} \mathrm{C}\end{array}$} & $\begin{array}{c}\text { Norm } \\
\text { (DIN EN } \\
\text { ISO 3104) }\end{array}$ & $\begin{array}{c}\text { Sample } \\
\mathbf{1 5 . 0 5 . 1 5}\end{array}$ & $\begin{array}{c}\text { Sample } \\
\mathbf{1 8 . 0 9 . 1 5}\end{array}$ & $\begin{array}{l}\text { Sample } \\
4.12 .15\end{array}$ & $\begin{array}{c}\text { Sample } \\
\text { 17.06.16 }\end{array}$ & $\begin{array}{c}\text { Sample } \\
20.10 .16\end{array}$ \\
\hline & $\begin{array}{c}\mathrm{KV}, \\
\mathrm{mm}^{2} / \mathrm{s}\end{array}$ & $\begin{array}{c}\mathrm{KV}, \\
\mathrm{mm}^{2} / \mathrm{s}\end{array}$ & $\begin{array}{c}\mathrm{KV}, \\
\mathrm{mm}^{2} / \mathbf{s}\end{array}$ & $\begin{array}{c}\mathrm{KV}, \\
\mathrm{mm}^{2} / \mathbf{s}\end{array}$ & $\begin{array}{c}\mathrm{KV}, \\
\mathrm{mm}^{2} / \mathbf{s}\end{array}$ & $\begin{array}{c}\mathrm{KV}, \\
\mathrm{mm}^{2} / \mathrm{s}\end{array}$ \\
\hline 40 & 320 & 346,50 & 348,92 & 371,61 & 373,85 & 359,46 \\
\hline 100 & 24,1 & 26,17 & 21,17 & 23,17 & 25,33 & 25,50 \\
\hline
\end{tabular}

Table. 3 wear Products, g/t

\begin{tabular}{|c|c|c|c|c|c|c|}
\hline Elements & $\begin{array}{c}\text { tolerancel } \\
\text { imits }\end{array}$ & $\begin{array}{c}\text { Sample } \\
\mathbf{1 5 . 0 5 . 1 5}\end{array}$ & $\begin{array}{c}\text { Sample } \\
\mathbf{1 8 . 0 9 . 1 5}\end{array}$ & $\begin{array}{c}\text { Sample } \\
\mathbf{4 . 1 2 . 1 5}\end{array}$ & $\begin{array}{c}\text { Sample } \\
\mathbf{1 7 . 0 6 . 1 6}\end{array}$ & $\begin{array}{c}\text { Sample } \\
\mathbf{2 0 . 1 0 . 1 6}\end{array}$ \\
\hline $\mathrm{Fe}$ & $126-200$ & 132,47 & 29,20 & 63,39 & 136,00 & 299,16 \\
\hline $\mathrm{Si}$ & $21-30$ & 35,05 & 35,68 & 39,81 & 42,24 & 51,24 \\
\hline $\mathrm{Cu}$ & $100-150$ & 3,09 & 6,25 & 1,09 & 7,81 & 7,13 \\
\hline $\mathrm{Al}$ & $4-7$ & 1,19 & 1,29 & 1,71 & 2,15 & 2,95 \\
\hline $\mathrm{Cr}$ & $2-5$ & 0,83 & 1,19 & 1,43 & 1,39 & 1,69 \\
\hline $\mathrm{Pb}$ & - & 3,73 & 1,33 & 3,49 & 4,44 & 4,03 \\
\hline $\mathrm{Sn}$ & - & 7,00 & 4,89 & 7,54 & 7,32 & 12,11 \\
\hline
\end{tabular}

Table. 4 flash point in open crucible

\begin{tabular}{|c|c|c|c|c|c|c|}
\hline Settings & $\begin{array}{c}\text { Norm } \\
\text { (DIN ISO } \\
2592)\end{array}$ & $\begin{array}{c}\text { Sample } \\
15.05 .15\end{array}$ & $\begin{array}{c}\text { Sample } \\
18.09 .15\end{array}$ & $\begin{array}{c}\text { Sample } \\
4.12 .15\end{array}$ & $\begin{array}{c}\text { Sample } \\
17.06 .16\end{array}$ & $\begin{array}{c}\text { Sample } \\
20.10 .16\end{array}$ \\
\hline $\begin{array}{c}\text { Temperature, } \\
{ }^{\circ} \mathrm{C}\end{array}$ & 255 & 238 & 236 & 228 & 216 & 235 \\
\hline
\end{tabular}

According to the data given in tables $1-4$, it can be noticed that the condition of the reducer is critical, there is a buildup of mechanical impurities in the oil to the limit values and exceeding the standards on the content of silicon ( $\mathrm{Si}$ ) and iron $(\mathrm{Fe})$. There is also a slight deviation of viscosity from normative values, as well as changing the flash point in open crucible oil. According to the obtained results of the oil analysis it is necessary to replace oil, to pay attention to the heating mode of operation and to avoid the entrainment of coal dust in the gearbox.

In this mode of service an individual approach to each piece of equipment is not applied. The reason is that in the process the oil undergoes a number of changes, some of which can reduce the reliability and durability of the movement. To avoid this, the manufacturer position maintenance regulation list of applicable lubricants and frequency of their replacement. However, it does not guarantee reducing performance oils, because the change in each mechanism occurs individually. Moreover, deterioration of the working oil is because of inappropriate quality of service transport unit.

Hence the need is to monitor the temperature regime of the oil in the operation of the control equipment and its technical condition and to prevent failures. The application of 
temperature as a diagnostic parameter of the working oil allows monitoring of the actual technical condition of the gearbox of a belt conveyor.

One of the most progressive methods of diagnostics of the temperature regime of today is recognized as thermal imaging diagnostics $[4,6]$. Its application is based on the fact that the presence of almost all kinds of defects in the equipment causes change of temperature of defective elements and, as a consequence, the change in the intensity of infrared radiation registering thermal imaging devices. The defect is detected by comparing temperatures of similar (neighboring) areas of the surface of parts and units working under the same conditions of heating and cooling. Thermal imaging detects defects at the earliest stage of their appearance and development that allows planning the scope and timing of repair. Decommissioning hardware is defective according to the results of its diagnosis, to its total rejection, greatly improves the reliability and safety of transport communications, and reduces significantly the loss of energy. The results of thermal monitoring of a gearbox of a belt conveyor are presented in table 5 and figure 1 .

Table. 5 Results of thermal imaging of the gearbox of a belt conveyor

\begin{tabular}{|c|c|c|c|}
\hline $\begin{array}{c}\text { The name of the } \\
\text { site }\end{array}$ & $\begin{array}{c}\text { Permitted } \\
\text { temperature, }{ }^{\circ} \mathbf{C}\end{array}$ & $\begin{array}{c}\text { The actual surface } \\
\text { temperature, }{ }^{\circ} \mathbf{C}\end{array}$ & $\begin{array}{c}\text { Actual } \\
\text { temperature of the } \\
\text { lubricant, }{ }^{\circ} \mathbf{C}\end{array}$ \\
\hline $\begin{array}{c}\text { Reducer } \\
\text { D3RST82XO }\end{array}$ & 106 & 79,7 & 97,7 \\
\hline
\end{tabular}

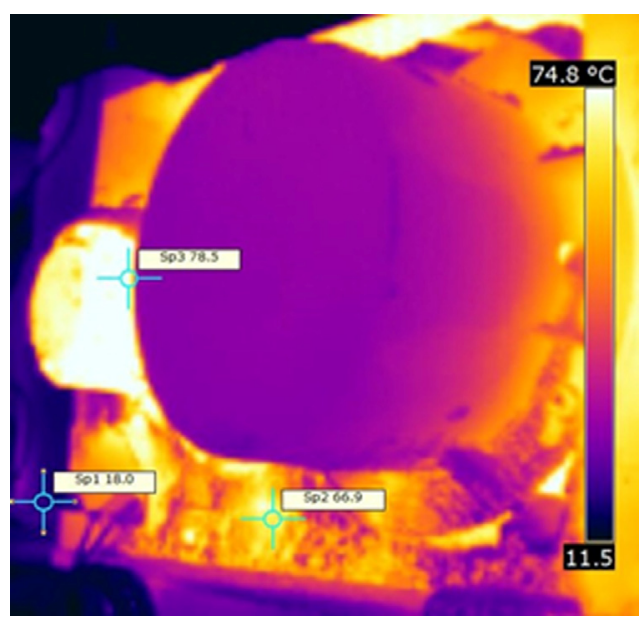

Fig. 1. Results of thermal imaging of the gearbox of a belt conveyor

The results of thermal imaging of the rollers of the gear shown in figure 2 (a, b, c, d). 


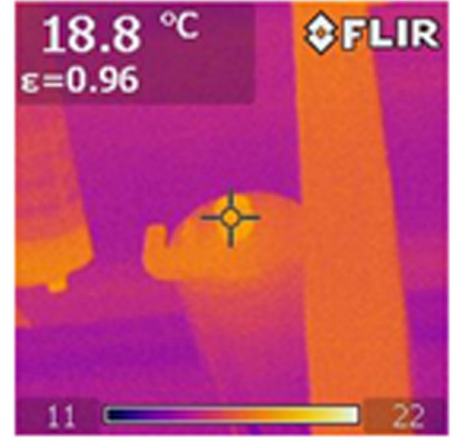

a)

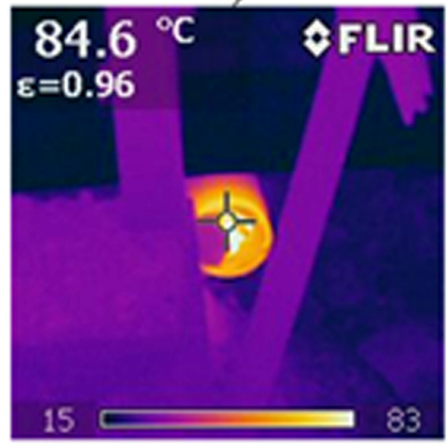

c)

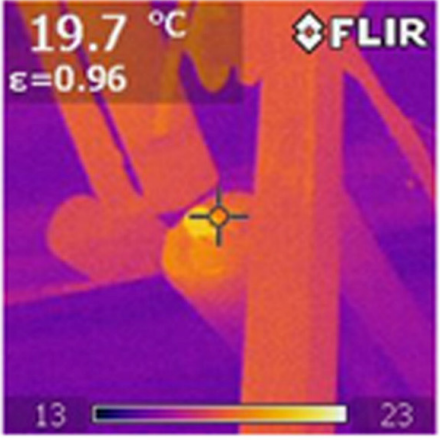

b)

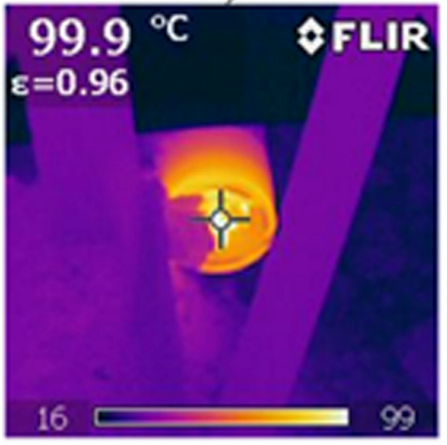

d)

Fig. 2. Results of thermal imaging rollers reducer

Evaluation criteria the results of thermal control are presented in table 6.

Table. 6 evaluation criteria the results of thermal control

\begin{tabular}{|c|c|c|}
\hline $\begin{array}{c}\text { Temperature } \\
\text { anomaly, } \mathbf{\Delta} \mathbf{T},{ }^{\circ} \mathbf{C}\end{array}$ & $\begin{array}{c}\text { Actual temperature } \\
\text { of the lubricant, }{ }^{\mathbf{C}}\end{array}$ & Evaluation criteria \\
\hline $0-5$ & Not more than 80 & CategoryA - good condition \\
\hline $5-10$ & $90-90$ & $\begin{array}{c}\text { Category B - limited working capacity } \\
\text { requires additional diagnosis }\end{array}$ \\
\hline $10-15$ & More then $100-110$ & $\begin{array}{c}\text { Category C - critical condition, surgical } \\
\text { intervention is required, additional } \\
\text { diagnostics }\end{array}$ \\
\hline More than 15 & $\begin{array}{c}\text { Category D - an unacceptable condition, the } \\
\text { possible damage, and surgical intervention is } \\
\text { required, possible repair. }\end{array}$ \\
\hline
\end{tabular}

The other rotating element of the equipment (e.g. a roller of belt conveyor) also affects the energy saving in haulage. The durability of the belt conveyor and its core components [8] depends on how easily rotates the roller. The more the non-rotating (jammed) rollers on the line, the higher the friction force between the defective roller and a tape sheet (which accelerates wear). This increases the load on the drive stations and the repeater drum, which also entails an increased wear of these elements and increase in energy consumption. 


\section{Conclusions}

Diagnostic performance characteristics of lubricant and temperature of the elements of equipment allows monitoring in time the technical condition of equipment and avoid premature failure, improves the efficiency of the transport system, and the enterprise as a whole.

\section{References}

1. Z. Sroka, Open Access Library Journal, 1, 1100816. (2014)

2. H.C. Thakur, International Journal of Scientific \& Engineering Research, 7:12, (2016)

3. Ying-Chieh Chou, Leehter Yao, Automatic Diagnosis System of Electrical Equipment using Infrared Thermography (Taipei University of Technology Taipei, Taiwan, R.O.C., 2010.)

4. A. Tawfik Saleh, Spectral Analysis Review 2:1, 43252,2 (2014)

5. L.I. Efimenko, M.P. Tichanskiy, KTU Bul. 25, 163 (2010)

6. R. Zimroz, W. Bartelmus, T. Barszcz, J. Urbanek, Mechanical Systems and Signal Processing, (2013)

7. R. Zimroz, R. Krol, M. Hardygora, J. Gorniak-Zimroz, W. Bartelmus, L. Gladysiewicz, S. Biernat, 22nd World Mining Congress \& Expo, 1, 433 (2011)

8. W. J. Bartelmus, Phys.: Conf. Ser., 305:1, 012029 (2011)

9. W. Bartelmus, F. Chaari, R. Zimroz, M. Haddar, European Journal of Mechanics., 29:4, 637 (2010)

10. A. Bellino, A. Fasana, L. Garibaldi, S. Marchesiello, Mechanical Systems and Signal Processing, 24:7, 2250 (2010) 